\title{
Acoustical Measurement and Biot Model for Coral Reef Detection and Quantification
}

\author{
Henry M. Manik \\ Department of Marine Science and Technology, Faculty of Fisheries and Marine Sciences, Bogor Agricultural University, \\ Kampus IPB Darmaga, Bogor 16680, Indonesia \\ Correspondence should be addressed to Henry M. Manik; henrymanik@ipb.ac.id
}

Received 15 November 2015; Accepted 3 February 2016

Academic Editor: Marc Asselineau

Copyright (C) 2016 Henry M. Manik. This is an open access article distributed under the Creative Commons Attribution License, which permits unrestricted use, distribution, and reproduction in any medium, provided the original work is properly cited.

Coral reefs are coastal resources and very useful for marine ecosystems. Nowadays, the existence of coral reefs is seriously threatened due to the activities of blast fishing, coral mining, marine sedimentation, pollution, and global climate change. To determine the existence of coral reefs, it is necessary to study them comprehensively. One method to study a coral reef by using a propagation of sound waves is proposed. In this research, the measurement of reflection coefficient, transmission coefficient, acoustic backscattering, hardness, and roughness of coral reefs has been conducted using acoustic instruments and numerical modeling using Biot theory. The results showed that the quantification of the acoustic backscatter can classify the type of coral reef.

\section{Introduction}

As an archipelago country, Indonesia has many types of coral reefs. Coral reefs consist of geological structures of calcium carbonate built over time by tiny living organisms. These structures are found in the marine waters which contain nutrients. Coral reefs had been used for marine tourism, shoreline protection, and fishing ground to the local communities. Coral reefs, which are called rainforests of the sea, are the most biologically diverse ecosystems. They support variety of marine live forms, provide pharmaceutical materials, and generate income from tourism [1].

Coral reefs are valuable marine resources; however, they are in the vulnerable condition [2]. In spite of their advantages and in spite of the fact that humans continue to benefit from coral reefs, the marine ecosystem has been subjected to serious anthropogenic threats. Nonsustainable activities and developments have inevitably caused degradation to the coral reef ecosystem. Blast fishing activities, mining of coral reef for building materials, and other threats like sedimentation and pollution in coastal areas are diminishing the ecosystem.

The greatest threats to coral reefs are rising seawater temperature and ocean acidification. With the recent global ocean warming, coral bleaching and mortality have become more frequent. Human induced disturbances, storm, and natural predators also affected the damage of coral reef [2].

However, the lack of accurate and comprehensive coral reef database has always been one of the limiting factors in their conservation and management efforts. The marine scientists and the coastal resource managers need to know the distribution and the status of these coral reefs.

State of the Art and Scientific Contribution. Detection and mapping of coral reef ecosystem should be at a scale that is adequate to detail information on the distribution of the major coral reef substrates. Unfortunately, the current coral reef research methodologies are still unable to fulfill this need. This is mainly due to the high cost involved and inherent shortcomings of the remote sensing technologies. The conventional coral reef research methods use a diver by applying the line transect, quadrate plot, belt transect, and manta tow survey [3]. All of these methods are used to derive both quantitative and qualitative data of coral reefs on a small scale surveyed area. In order to produce contiguous, broad scale resource map, marine scientists have explored the underwater videography and LIDAR survey using airborne and satellite remote sensing [4]. 


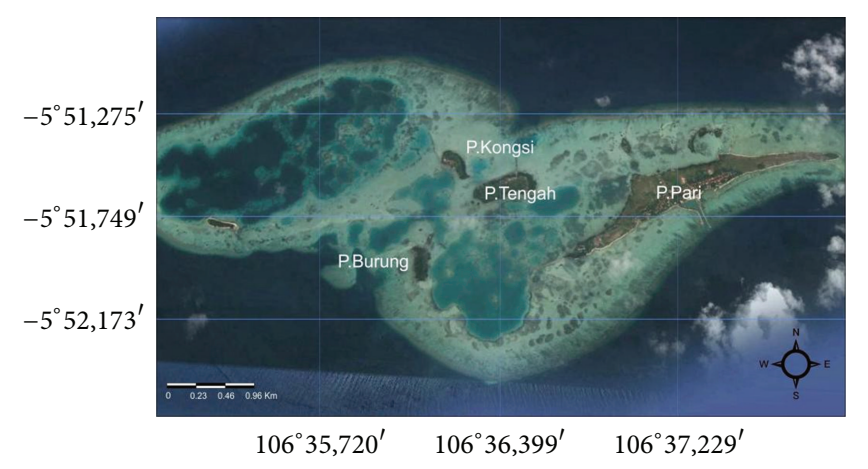

FIGURE 1: Research location in Seribu Island waters.

These methods yield different degrees of resolution and accuracy depending on the sensor type, cost, time, ground truthing, and postprocessing. LIDAR airborne and satellite remote sensing derived images. Several researchers mapped the coral reef using satellite remote sensing [5]. This remote sensing technology was originally designed for terrestrial application. A number of limitations become obvious, when remote sensing is applied to map underwater marine resources. The electromagnetic wave used in satellite remote sensing was more absorbed in ocean environment.

To overcome this problem, the application of underwater acoustic technologies is used to detect and quantify coral reef. Acoustic technologies offer a promising method for underwater remote sensing techniques [6-8]. The sound waves can propagate deeper compared with electromagnetic wave. This method allows for large area coverage in greater details within a shorter time at a relatively low cost. Acoustic detection using side scan sonar and multibeam echosounder has been successful for water column and seabed imaging $[9,10]$. Bottom backscattering strength was computed for acoustic seabed classification [11, 12].

The objective of this research is to develop a methodology for effective ecosystem monitoring and mapping of tropical marine coral reefs using underwater acoustic technology in Seribu Island waters, Indonesia.

\section{Research Method}

The research was conducted at Ocean Acoustics and Instrumentation Laboratory, Department of Marine Science and Technology, Faculty of Fisheries and Marine Sciences, Bogor Agricultural University, and Seribu Island waters, Jakarta, Indonesia (Figure 1).

2.1. Flow Diagram of the Research. The flow diagram of this research in the laboratory is shown in Figure 2. Research output is to develop and apply the methodology of high resolution underwater acoustic technology, calibrating the instrument and measuring acoustic backscattering from coral reef.
2.2. Hydroacoustic Data Acquisition, Processing, and Analysis. Based on underwater acoustic theory, the ability of this method is applied to discriminate coral reef types, to map coral substrates, and to measure acoustic reflectivity of coral reef at Seribu Island waters. The result encourage where the acoustic instrument was able to pick up distinct echo when ensonifying over coral reef type. All ocean surveys were conducted on the research vessel. The ship is outfitted with a suite of underwater acoustics instrument. Matlab software was applied and used in postprocessing and visualization to overlay pings and backscatter returns in both space and time.

Raw data was corrected for ambient noise and interference artifacts. A subset of pings were identified in the acoustic data and concurrent pings are selected in the acoustic data records. Coral reef detection algorithms were developed and used in Matlab to delineate bottom fish and seabed backscatter.

Consecutive echoes representing individual coral are similarly delineated in the hydroacoustic image. In the case of dense coral, tracks are selected on the outer limits of the coral. The average backscattering strength is calculated for the series of echoes. Figure 3 shows a simplified block diagram for coral reef backscattering measurement by quantitative echo sounder.

The backscattered pressure signal from the bottom received by the transducer (Figure 3), $P_{\mathrm{RB}}[12]$, is

$$
P_{\mathrm{RB}}^{2}=P_{o} r^{-2} \exp (-4 \alpha r) \Phi S_{S}
$$

where $P_{o}$ is the source pressure level.

The bottom echo signal is amplified by the amplifier to give

$$
E_{\mathrm{RB}}=P_{\mathrm{RB}} M G_{R}
$$

where $E_{\mathrm{RB}}$ is the echo amplitude at the preamplifier output, $M$ is the receiving sensitivity of the transducer, and $G_{R}$ is the preamplifier gain.

The echo amplitude, $E_{\mathrm{RB}}$, is shown from (1) and (2) as

$$
E_{\mathrm{RB}}^{2}=K_{\mathrm{TR}}^{2} r^{-2} \exp (-4 \alpha r) \Phi S_{S},
$$

where $K_{\mathrm{TR}}=P_{o} M G_{R}$ is the transmitting receiving coefficient. 


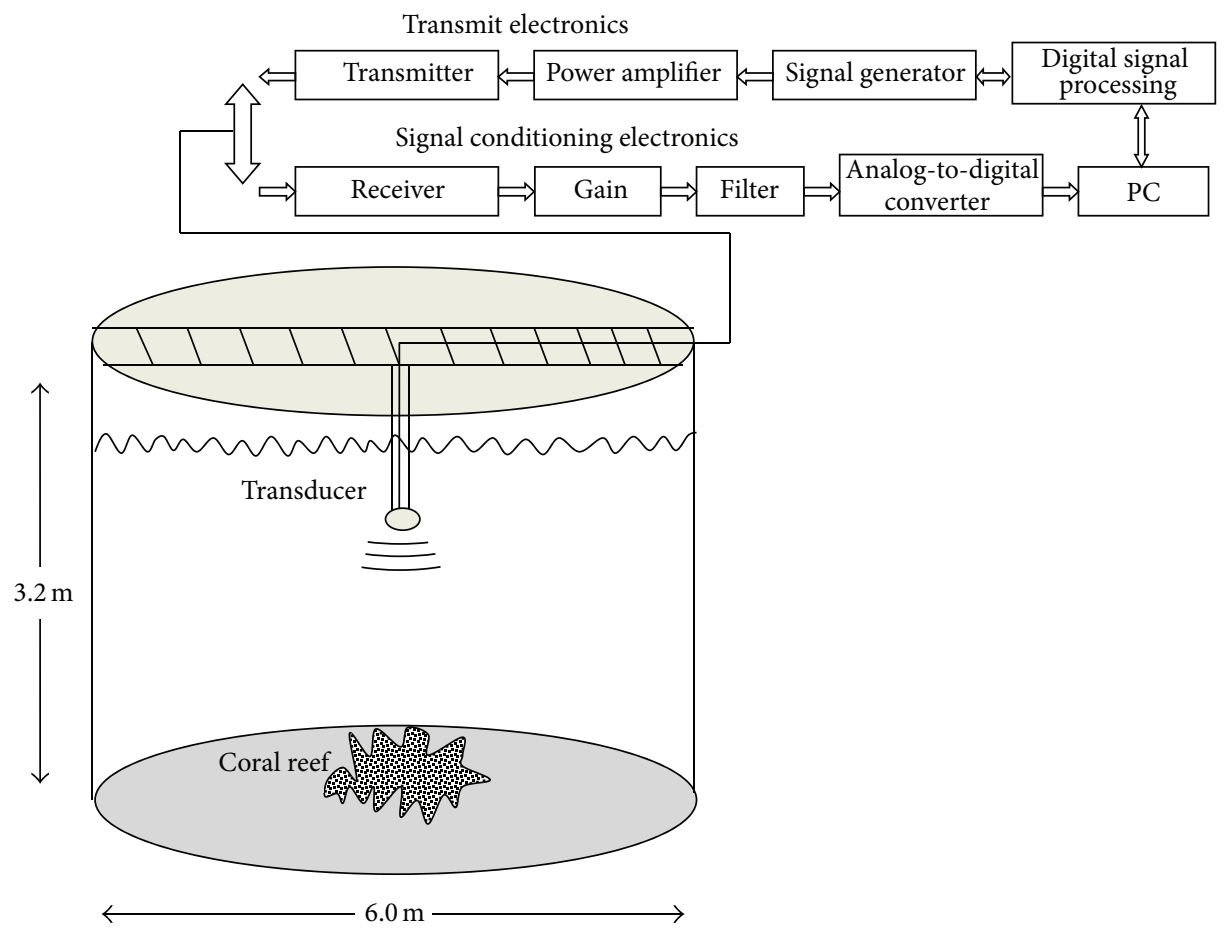

FigURE 2: Flow diagram of underwater acoustic instrument for measuring coral reef.

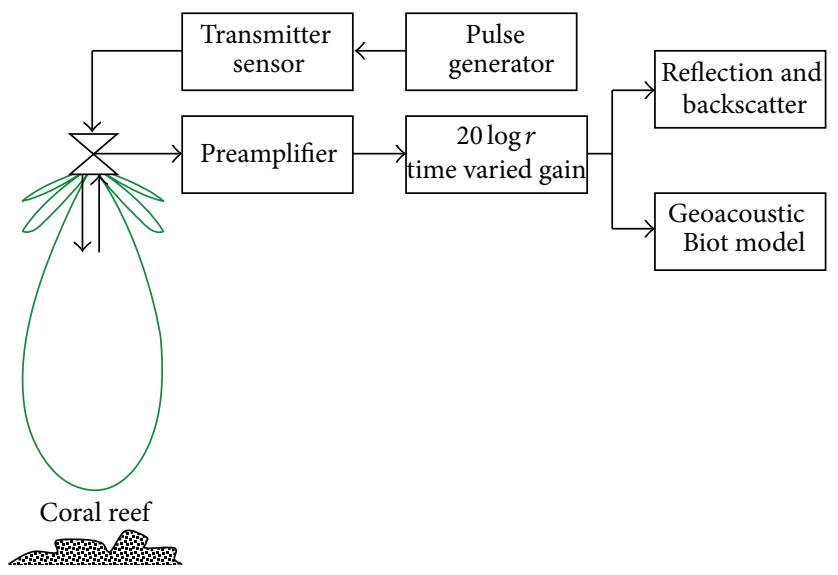

FIgURE 3: Methodology of acoustical measurement and Biot model.

The time varied gain (TVG) amplifier output of $E_{\mathrm{RB}}$ corrected for absorption and spreading losses, $E_{\mathrm{TB}}$, is

$$
\begin{aligned}
& E_{\mathrm{TB}}=G_{\mathrm{TM}} r \exp (2 \alpha r) E_{\mathrm{RB}}, \\
& E_{\mathrm{TB}}^{2}=\left(K_{\mathrm{TR}} G_{\mathrm{TM}}\right)^{2} \Phi S_{S} .
\end{aligned}
$$

The raw SV value of the bottom echo, $S_{\mathrm{VB}}$, is

$$
S_{\mathrm{VB}}=\frac{E_{\mathrm{TB}}^{2}}{K_{M}^{2}},
$$

where $K_{M}$ is the multiple echo coefficient and is given by

$$
K_{M}^{2}=\left(K_{\mathrm{TR}} G_{\mathrm{TM}}\right)^{2} \Psi\left(\frac{c \tau}{2}\right),
$$

where

$$
\Psi=\int_{0}^{2 \pi} \int_{0}^{\pi / 2} b^{2} \sin \theta d \theta d \phi
$$




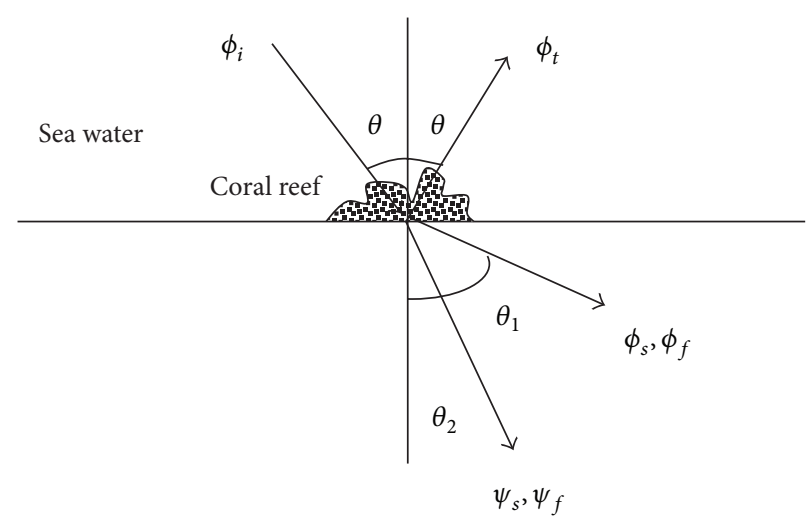

FIGURE 4: Incident, reflected, and transmitted wave in seawater and coral reef.

The above $\Psi$ is the equivalent beam angle of the volume scattering.

Substitution of $E_{\mathrm{TB}}$ and $K_{M}$ into (6) yields

$$
S_{\mathrm{VB}}=\frac{S_{S} \Phi}{\Psi(c \tau / 2)}
$$

This equation is called ring surface scattering model.

2.3. Geoacoustic Biot Model. Coral reefs are porous, with the possibility that the fluid and granular phases will vibrate differently in response to acoustic excitation. Poroelastic theory or Biot theory treats both porosity and elasticity [13, $14]$.

The incident and reflected waves in the seawater and coral will have displacement potential (Figure 4):

$$
\begin{aligned}
& \phi_{i}=A_{i} \exp \left[j\left(\omega t-k_{w} \cos \theta \cdot z-k_{w} \sin \theta \cdot x\right)\right], \\
& \phi_{r}=A_{r} \exp \left[j\left(\omega t+k_{w} \cos \theta \cdot z-k_{w} \sin \theta \cdot x\right)\right],
\end{aligned}
$$

where $k_{w}=\omega / c_{w}$. $\omega$ is the angular frequency, and $c_{w}$ is the sound velocity in the seawater.

Biot developed a pair of coupled differential equations to describe acoustic wave propagation in an isotropic saturated porous medium with permeability $\kappa$, pore fluid viscosity $\eta$, and bulk density $\rho_{f}$ :

$$
\begin{aligned}
\nabla^{2}(H \varepsilon-C \varsigma) & =\frac{\partial^{2}}{\partial t^{2}}\left(\rho \varepsilon-\rho_{f} \varsigma\right), \\
\nabla^{2}(C \varepsilon-M \varsigma) & =\frac{\partial^{2}}{\partial t^{2}}\left(\rho_{f} \varepsilon-m \varsigma\right)-\frac{F \eta}{\kappa} \frac{\partial \varsigma}{\partial t},
\end{aligned}
$$

where $\varsigma$ is the incremental volume of fluid which enters or leaves the frame and $\varepsilon$ is the volumetric strain of the frame. Stoll developed the theory for Biot moduli in terms of measurable sediment properties:

$$
\begin{aligned}
& H=\frac{\left(K_{r}-K_{b}\right)^{2}}{D-K_{b}}+K_{b}+\frac{4}{3} \mu, \\
& C=\frac{K_{r}\left(K_{r}-K_{b}\right)^{2}}{D-K_{b}}, \\
& M=\frac{K_{r}^{2}}{D-K_{b}}, \\
& D=K_{r}\left(1+n\left(\frac{K_{r}}{K_{f}}-1\right)\right),
\end{aligned}
$$

where $K_{r}$ is the grain bulk modulus, $K_{f}$ is the modulus of the pore fluid, and $\eta$ is porosity. The frame bulk modulus was calculated by

$$
K_{b}=K_{b r}+j K_{b i}=K_{b r}\left(1+j \frac{\delta_{b}}{\pi}\right)
$$

and the frame shear modulus was calculated by

$$
\mu=\mu_{r}+j \mu_{i}=\mu_{r}\left(1+j \frac{\delta_{s}}{\pi}\right),
$$

where $\delta_{b}$ and $\delta_{s}$ are the bulk and shear logarithmic decrement.

The boundary conditions are required at a seawater-coral reef interface.

(1) For continuity of fluid movement

$$
\frac{\partial \phi_{i}}{\partial z}+\frac{\partial \phi_{r}}{\partial z}=\frac{\partial \phi_{s}}{\partial z}+\frac{\partial \psi_{s}}{\partial x}-\frac{\partial \phi_{f}}{\partial z}-\frac{\partial \psi_{f}}{\partial x} .
$$

(2) For equilibrium of normal traction

$$
\begin{aligned}
& H\left(\frac{\partial^{2} \phi_{i}}{\partial x^{2}}+\frac{\partial^{2} \phi_{s}}{\partial z^{2}}\right)-2 \mu\left(\frac{\partial^{2} \phi_{s}}{\partial x^{2}}-\frac{\partial^{2} \psi_{s}}{\partial x \partial z}\right) \\
& -C\left(\frac{\partial^{2} \phi_{f}}{\partial x^{2}}+\frac{\partial^{2} \phi_{t}}{\partial z^{2}}\right)=\rho_{f}\left(\frac{\partial^{2} \phi_{i}}{\partial t^{2}}+\frac{\partial^{2} \phi_{r}}{\partial t^{2}}\right) .
\end{aligned}
$$




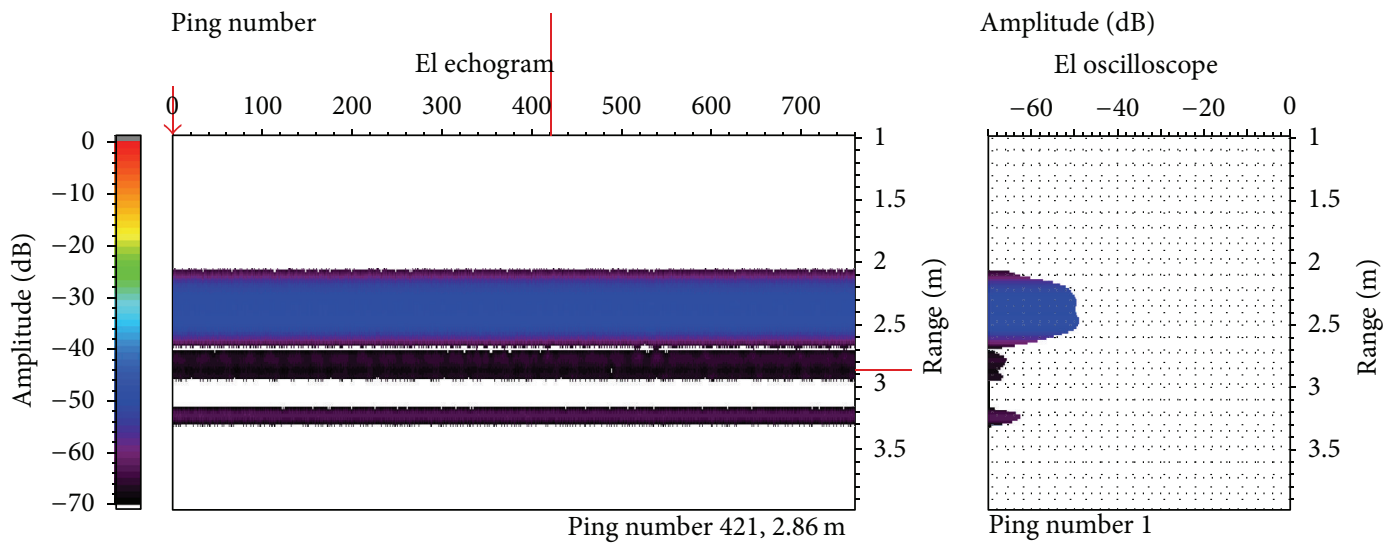

FIGURE 5: Acoustic calibration using sphere ball.

For equilibrium of fluid pressure

$$
\begin{aligned}
& M\left(\frac{\partial^{2} \phi_{f}}{\partial x^{2}}+\frac{\partial^{2} \phi_{f}}{\partial z^{2}}\right)-C\left(\frac{\partial^{2} \phi_{s}}{\partial x^{2}}+\frac{\partial^{2} \phi_{s}}{\partial z^{2}}\right) \\
& \quad=-\rho_{f}\left(\frac{\partial^{2} \phi_{i}}{\partial t^{2}}+\frac{\partial^{2} \phi_{r}}{\partial t^{2}}\right),
\end{aligned}
$$

where $M=K_{t}^{2} /\left(D-K_{b}\right)$.

(3) For equilibrium of tangential traction

$$
2 \mu \frac{\partial^{2} \phi_{s}}{\partial x \partial z}-\mu\left(\frac{\partial^{2} \psi_{s}}{\partial z^{2}}-\frac{\partial^{2} \psi_{s}}{\partial x^{2}}\right)=0
$$

Four linear complex equations can be obtained for acoustic reflection measurement:

$$
\left(\begin{array}{llll}
c_{11} & c_{12} & c_{13} & c_{14} \\
c_{21} & c_{22} & c_{23} & c_{24} \\
c_{31} & c_{32} & c_{33} & c_{34} \\
c_{41} & c_{42} & c_{43} & c_{44}
\end{array}\right)\left(\begin{array}{c}
A_{1} \\
A_{2} \\
A_{3} \\
A_{4}
\end{array}\right)=\left(\begin{array}{c}
Y_{1} \\
Y_{2} \\
Y_{3} \\
Y_{4}
\end{array}\right)
$$

where the components of $\{c\}$ and $\{Y\}$ are given by the physical parameters of seawater and coral. $A_{r}$ is the complex amplitude of the reflected wave. The reflection coefficient can be computed from this equation. Physical parameters for coral reef models were shown in Table 1.

\section{Results and Analysis}

In order to obtain accurate and precise quantitative measurements of coral reef resources, proper calibration of an acoustic system is necessary when using acoustic techniques such as echo detection and echo integration. Figure 5 shows the acoustic calibration using sphere ball method. The blue color shows the sphere detected on $-42.5 \mathrm{~dB}$ and this value agreed
TABLE 1: Physical parameters for coral reef models.

\begin{tabular}{lcc}
\hline Physical parameters & Soft coral & Hard coral \\
\hline Grain diameter, $\phi$ & 5.2 & 1.5 \\
$d(\mathrm{~mm})$ & 0.022 & 0.453 \\
Grain density, $\rho_{r}\left(\mathrm{~kg} / \mathrm{m}^{3}\right)$ & 2,675 & 2,675 \\
Bulk modulus, $K_{r}(\mathrm{~Pa})$ & $3.6 \times 10^{10}$ & $3.6 \times 10^{10}$ \\
Density of pore fluid, $\rho_{f}\left(\mathrm{~kg} / \mathrm{m}^{3}\right)$ & 1,000 & 1,000 \\
Bulk modulus of pore fluid, $K_{f}(\mathrm{~Pa})$ & $2.25 \times 10^{9}$ & $2.25 \times 10^{9}$ \\
Viscosity, $\eta(\mathrm{Pa}-\mathrm{s})$ & $1.00 \times 10^{-3}$ & $1.00 \times 10^{-3}$ \\
Porosity, $\beta$ & 0.82 & 0.33 \\
Permeability, $\kappa\left(\mathrm{m}^{2}\right)$ & $4.45 \times 10^{-12}$ & $8.06 \times 10^{-11}$ \\
Pore size, $a(\mathrm{~m})$ & $1.30 \times 10^{-5}$ & $7.35 \times 10^{-5}$ \\
Structure factor, $\alpha$ & 1.30 & 1.30 \\
Bulk modulus of frame, $K_{b r}(\mathrm{~Pa})$ & $1.45 \times 10^{7}$ & $5.8 \times 10^{7}$ \\
Bulk logarithmic decrement, $\delta$ & 0.15 & 0.15 \\
Shear modulus, $\mu_{r}(\mathrm{~Pa})$ & $4.45 \times 10^{6}$ & $9.45 \times 10^{6}$ \\
Shear logarithmic decrement, $\delta_{s}$ & 0.16 & 0.16 \\
\hline
\end{tabular}

with the theoretical value obtained by the manufacturer. The result of calibration was shown in Table 2.

Acoustic data were collected using four frequencies (10, 50,100 , and $200 \mathrm{kHz}$ ) and pulse transmission was simultaneous at all frequencies. All transducers were suspended from a small boat and data were collected while drifting slowly over $15-40 \mathrm{~m}$ deep water. During the $6 \mathrm{~h}$ of data collection, the boat drifted approximately $3 \mathrm{~km}$. Figure 6 shows the acoustic image of soft coral and hard coral. The amplitude intensity for soft coral ranged from -35.0 to $-30.0 \mathrm{~dB}$ and that for hard coral ranged from -28.0 to $-10.0 \mathrm{~dB}$.

The hardness and roughness of coral reefs were shown in Figure 7. The hardness of soft coral ranged from $-33.0 \mathrm{~dB}$ to $-15.0 \mathrm{~dB}$ (Figure $7(\mathrm{a})$ ) and the hardness of hard coral was about $-22.0 \mathrm{~dB}$ to $-15.0 \mathrm{~dB}$. The roughness of soft coral 
TABLE 2: Configuration of the four acoustic frequencies.

\begin{tabular}{|c|c|c|c|c|c|c|c|}
\hline Frequency $(\mathrm{kHz})$ & Type of beam & $\begin{array}{l}\text { Half-power } \\
\text { beam width } \\
\left(^{\circ}\right)\end{array}$ & $\begin{array}{l}\text { Source level at } \\
1 \mathrm{~m}(\mathrm{~dB} \text { re } 1 \mu \mathrm{Pa})\end{array}$ & $\begin{array}{c}\text { Acoustic } \\
\text { power }(W)\end{array}$ & $\begin{array}{l}\text { Pulse length } \\
\text { (ms) }\end{array}$ & $\begin{array}{c}\text { Noise level } \\
\text { (dB) at } 1 \mathrm{~m} \\
\text { depth }\end{array}$ & $\begin{array}{l}\text { Absorption } \\
(\mathrm{dB} / \mathrm{km})\end{array}$ \\
\hline 10 & Single & $7.0 \times 6.9$ & 219.8 & 100 & 0.512 & -142 & 0.45 \\
\hline 50 & Single & $7.2 \times 7.3$ & 216.9 & 150 & 0.512 & -141 & 4.5 \\
\hline 100 & Single & $6.5 \times 6.5$ & 217.5 & 80 & 0.512 & -138 & 12.4 \\
\hline 200 & Split & $5.4 \times 5.4$ & 218.5 & 60 & 0.500 & -122 & 57.5 \\
\hline
\end{tabular}

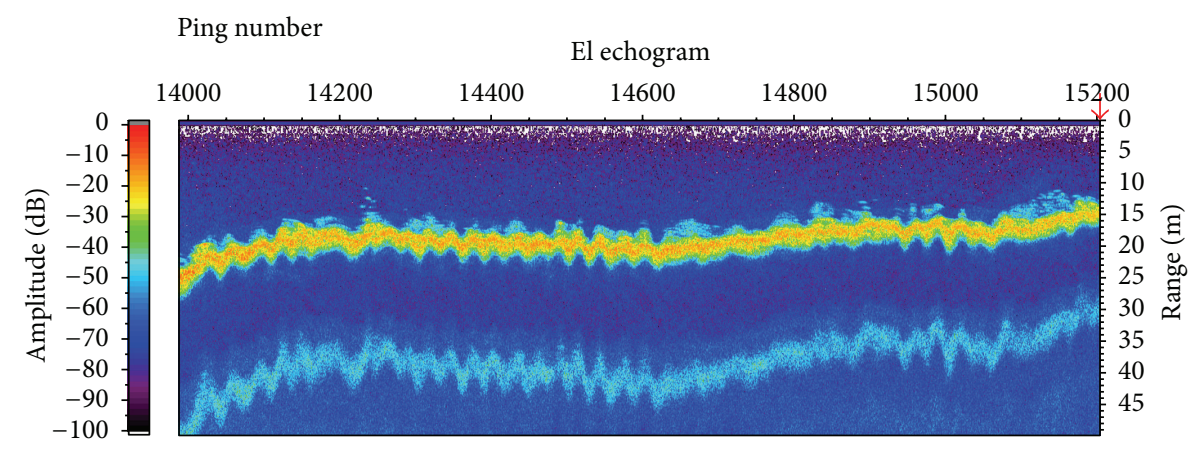

(a)

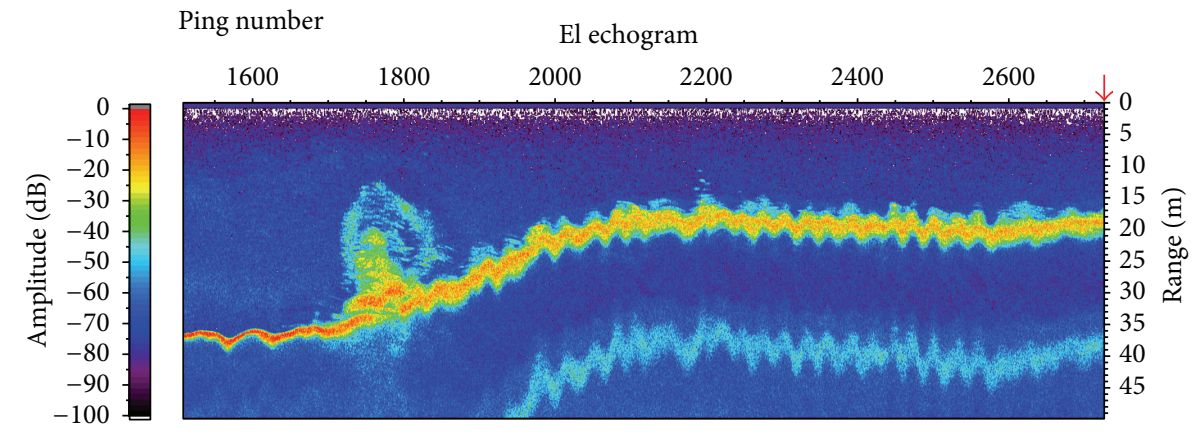

(b)

Figure 6: Acoustic image of soft coral reef (a) and hard coral reef (b).

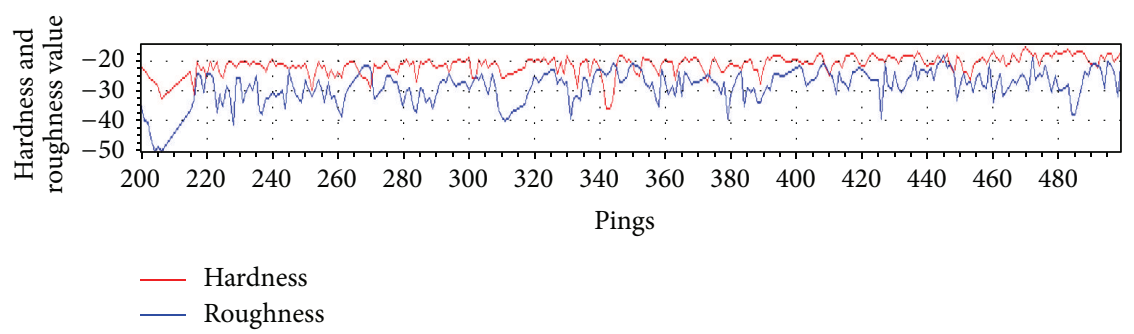

(a)

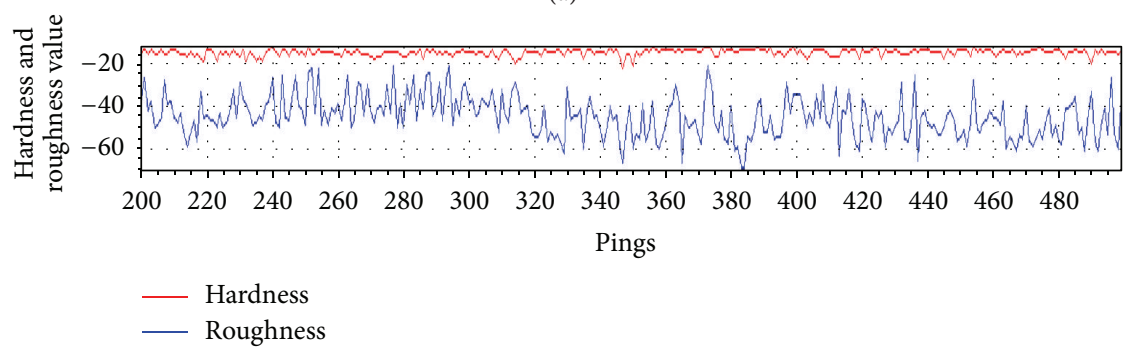

(b)

FIgURE 7: Hardness and roughness of coral reef. 


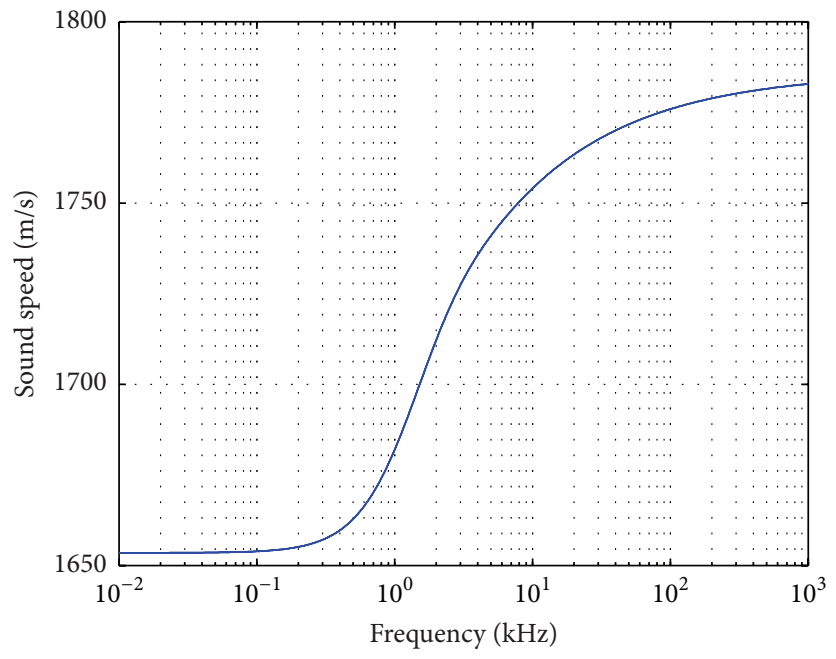

Figure 8: Sound speed as a function of frequency calculated using the Biot model.

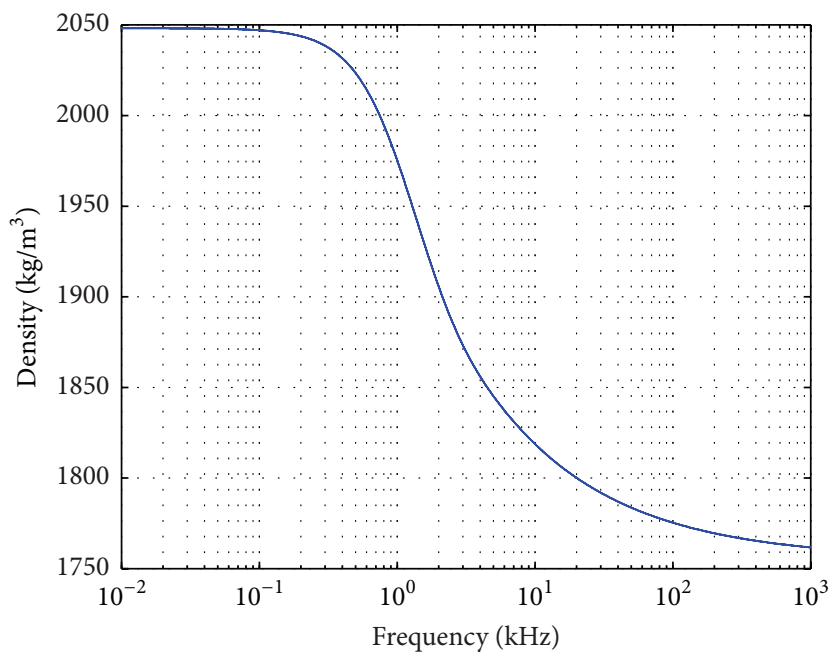

FIGURE 9: Density as a function of frequency calculated using the Biot model.

ranged from -50.0 to $-20.0 \mathrm{~dB}$ and that of hard coral ranged from -65.0 to $-22.0 \mathrm{~dB}$. The harder coral had more energy due to higher acoustic impedance compared to soft coral. However, a very rough and hard surface can scatter much energy acoustically $[15,16]$.

The parameters in Table 1 were used to examine the behavior of the density as a function of frequency. Figure 8 showed a plot of the real parts of the sound speed as a function of frequency from $0.01 \mathrm{~Hz}$ to $1000 \mathrm{kHz}$. At low frequencies, the pore size parameter is smaller than the viscous skin depth and at high frequencies the skin depth is smaller than the pore size [17].

Figures 9 and 10 show the density and attenuation as a function of frequency for Biot model. The bulk and shear moduli of the frame obviously increase the sound speed slightly. The effect of the larger difference in sound speed will be seen in the reflection, transmission, and backscattering strength.

The attenuation due to water viscosity in Biot model varies as frequency squared up to around $1 \mathrm{kHz}$. The attenuation due to frame moduli varies linearly with frequency. Numerical computation of Biot model confirms that the sound speed, density, and attenuation were frequency dependent.

Figure 11 shows the reflection coefficient as a function of grazing angle for four different frequencies $(10,50,100$, and $200 \mathrm{kHz}$ ) for the measurement and Biot model. The measurement of reflection coefficient was conducted by using the average intensity of the coral reef-water interface echo. The biggest difference is near the critical angle 


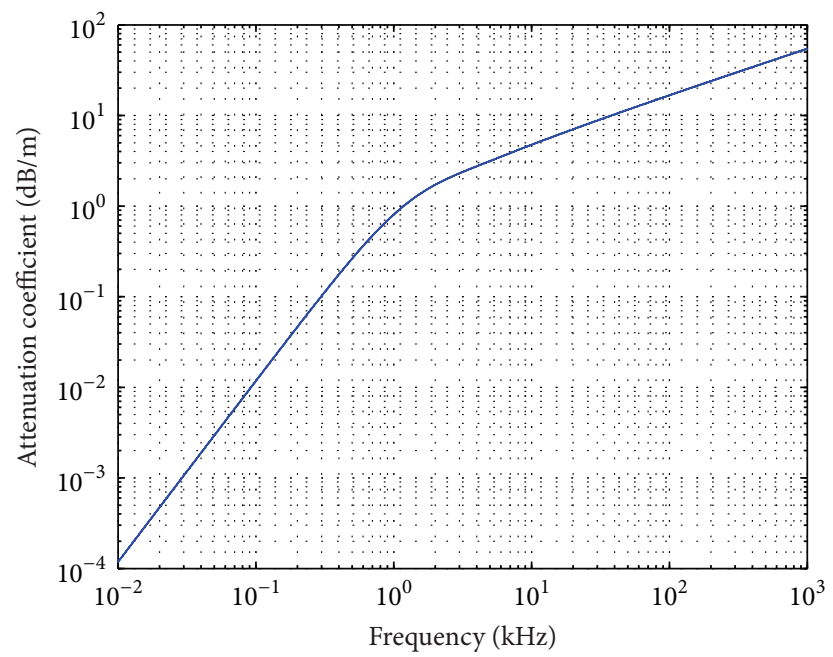

Figure 10: Attenuation coefficient as a function of frequency calculated using the Biot model.
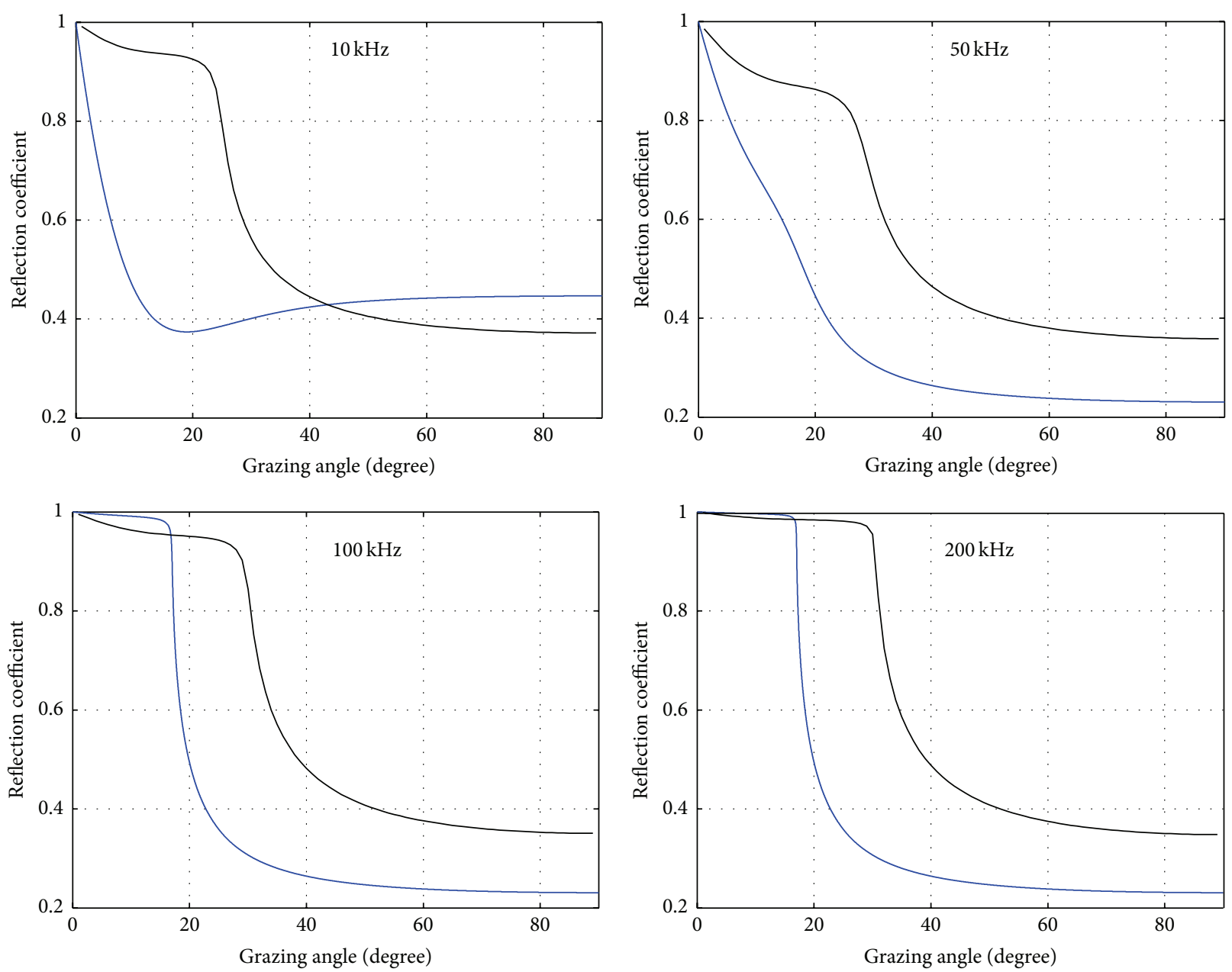

Figure 11: Reflection coefficient using Biot's model as a function of grazing angle at four different frequencies for soft coral (blue line) and hard coral (black line). 

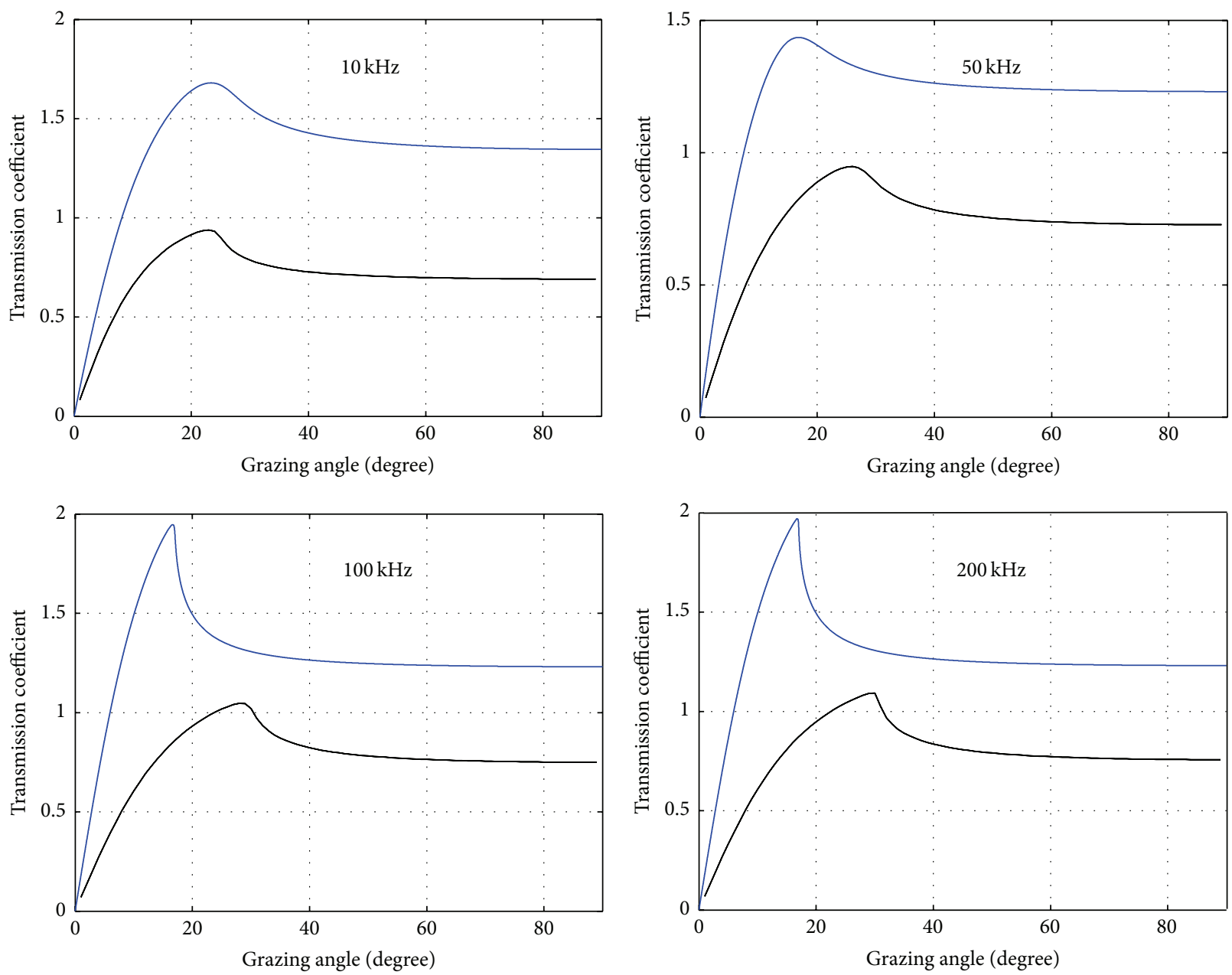

FIGURE 12: Transmission coefficient using Biot's model as a function of grazing angle at four different frequencies for soft coral (blue line) and hard coral (black line).

(near $20^{\circ}$ to $30^{\circ}$ ) and this is due to the difference in sound speed between coral reef and seawater. The reflection coefficient is strongly correlated with sediment porosity and bulk density. Based on this research, the porosity of the coral reef was estimated using the reflection coefficient.

The general trend for the transmission coefficient is shown in Figure 12. For the Biot model, the procedure used to calculate the transmitting coefficient using the scalar potential and fast wave. This figure means more energy is transmitted to the coral reef than reflected.

Figure 13 showed the backscattering strength as a function of grazing angle. Backscattering is dependent on many confounding parameters such as the coral composition, surface roughness, slope, and spatial heterogeneity of coral. Backscattering versus grazing angle can be exploited to detect differences in coral properties and to solve geoacoustic model of coral properties. Frequency response may indicate coral reef type. The objective of our study was to quantify backscattering for coral versus both frequency and grazing angle and to use parameters of Biot model to identify the type of coral reef. Backscattering strength of hard coral was higher than that of soft coral. These results were agreed on by previous researchers $[8,18]$.

\section{Conclusion}

Underwater acoustic remote sensing measurement and Biot model had been used to detect and quantify the coral reefs. The hardness of hard coral was higher than that of soft coral. The roughness of coral contributed to reflectivity and backscattering energy. Numerical computation of Biot model confirms that the sound speed, density, and attenuation are frequency dependent. Acoustic measurement agreed with Biot model in reflection and backscattering value of coral reef. This remote acoustic measurement and Biot model may be useful for estimating coral reef properties when core data are not available. 

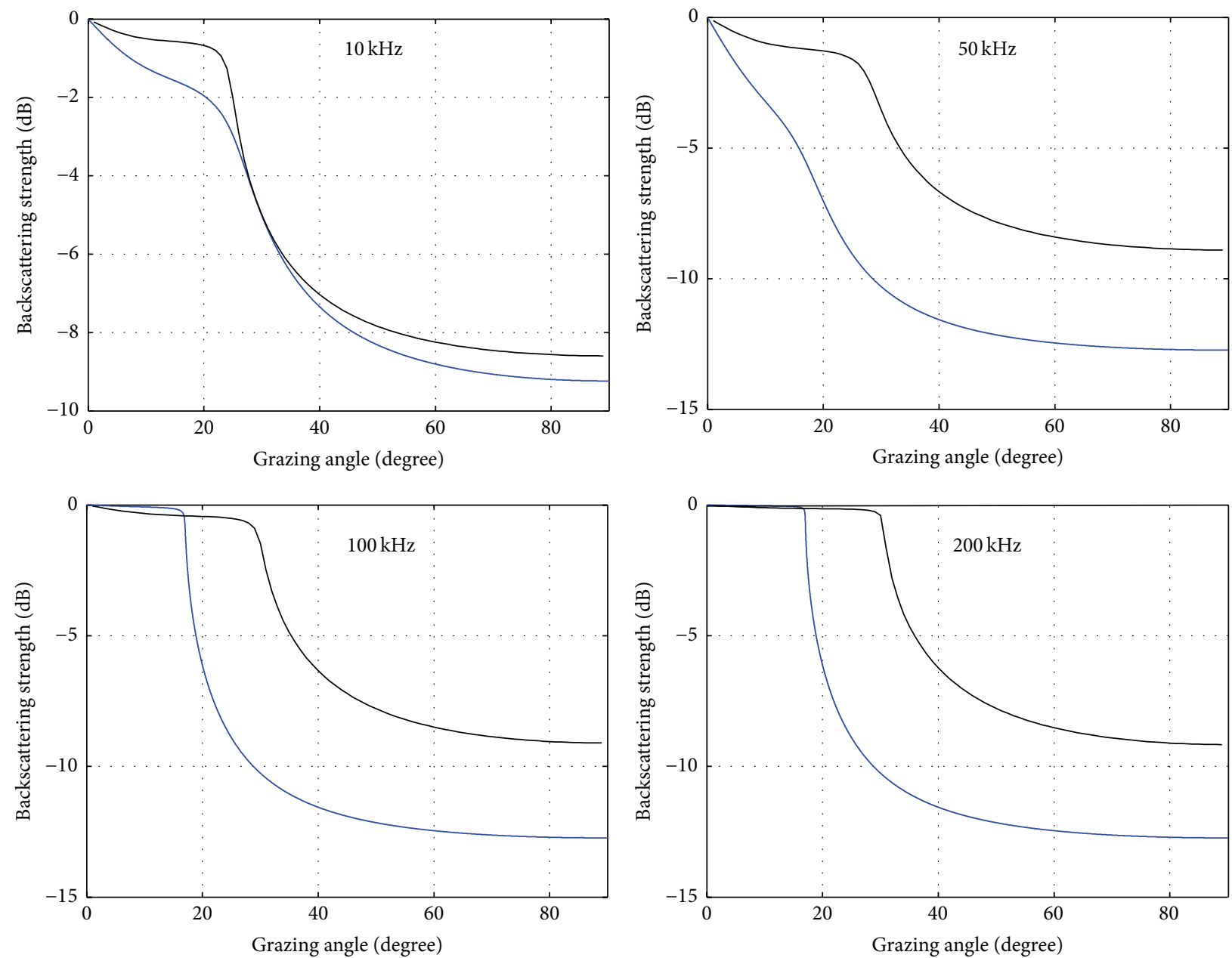

FIGURE 13: Backscattering strength as a function of grazing angle at four different frequencies for soft coral (blue line) and hard coral (black line).

\section{Competing Interests}

The author declares that there are no competing interests regarding the publication of this paper.

\section{Acknowledgments}

The author would like to thank the Indonesian Ministry of Research, Technology, and Higher Education and SEAMEO BIOTROP for sponsoring this research. The author wishes to acknowledge the many helpful discussions with Professor Darrell Jackson and Dr. Kevin L. Williams at Applied Physics Laboratory, University of Washington, USA, and Professor Masao Kimura at Poro-Acoustics Laboratory, Shimizu, Japan.

\section{References}

[1] N. A. Farmer, J. S. Ault, S. G. Smith, and E. C. Franklin, "Methods for assessment of short-term coral reef fish movements within an acoustic array," Movement Ecology, vol. 1, article 7, 2013.
[2] A. J. Irigoyen, D. E. Galván, L. A. Venerus, and A. M. Parma, "Variability in abundance of temperate reef fishes estimated by visual census," PLoS ONE, vol. 8, no. 4, Article ID e61072, 2013.

[3] D. Mallet and D. Pelletier, "Underwater video techniques for observing coastal marine biodiversity: a review of sixty years of publications (1952-2012)," Fisheries Research, vol. 154, pp. 4462, 2014.

[4] C. J. Brown, S. J. Smith, P. Lawton, and J. T. Anderson, "Benthic habitat mapping: a review of progress towards improved understanding of the spatial ecology of the seafloor using acoustic techniques," Estuarine, Coastal and Shelf Science, vol. 92, no. 3, pp. 502-520, 2011.

[5] P. T. Harris and E. K. Baker, "GeoHab Atlas of seafloor geomorphic features and benthic habitats-synthesis and lessons learned," in Seafloor Geomorphology as Benthic Habitat: GeoHab Atlas of Seafloor Geomorphic Features and Benthic Habitats, P. T. Harris and E. K. Baker, Eds., pp. 871-888, Elsevier, Amsterdam, The Netherlands, 2011.

[6] D. Ierodiaconou, J. Monk, A. Rattray, L. Laurenson, and V. L. Versace, "Comparison of automated classification techniques for predicting benthic biological communities using hydroacoustics and video observations," Continental Shelf Research, vol. 31, no. 2, pp. S28-S38, 2011. 
[7] V. M. Trenkel, P. H. Ressler, M. Jech, M. Giannoulaki, and C. Taylor, "Underwater acoustics for ecosystem-based management: state of the science and proposals for ecosystem indicators," Marine Ecology Progress Series, vol. 442, pp. 285-301, 2011.

[8] H. M. Manik, "Shallow-water acoustics investigations for underwater detection and seabed imaging," International Journal of Applied Engineering Research, vol. 10, no. 17, pp. 3830238307, 2015.

[9] H. M. Manik, "Acoustic characterization of fish and seabed using underwater acoustics technology," International Journal of Oceans and Oceanography, vol. 9, no. 1, pp. 77-95, 2015.

[10] H. M. Manik, D. Yulius, and Udrekh, "Development and application of MB system software for bathymetry and seabed computation," International Journal of Software Engineering and its Applications, vol. 9, no. 6, pp. 143-160, 2015.

[11] H. M. Manik, S. Rohman, and D. Hartoyo, "Underwater multiple objects detection and tracking using multibeam and side scan sonar," International Journal of Applied Information System, vol. 2, no. 2, pp. 1-4, 2014.

[12] H. M. Manik, "Seabed identification and characterization using sonar," Advances in Acoustics and Vibration, vol. 2012, Article ID 532458, 5 pages, 2012.

[13] M. A. Zimmer, L. D. Bibee, and M. D. Richardson, "Measurement of the frequency dependence of the sound speed and attenuation of seafloor sands from 1 to $400 \mathrm{kHz}$," IEEE Journal of Oceanic Engineering, vol. 35, no. 3, pp. 538-557, 2010.

[14] R. D. Stoll and T.-K. Kan, "Reflection of acoustic waves at a water-sediment interface," The Journal of the Acoustical Society of America, vol. 70, no. 1, pp. 149-156, 1981.

[15] N. P. Chotiros, "Reflection and reverberation in normal incidence echo-sounding," Journal of the Acoustical Society of America, vol. 96, no. 5, pp. 2921-2929, 1994.

[16] N. P. Chotiros, "Inversion and sandy ocean sediments," in Full Field Inversion Methods in Ocean and Seismo-Acoustics, O. Diachok, A. Caiti, P. Gerstoft, and H. Schmidt, Eds., pp. 353358, Kluwer, Norwell, Mass, USA, 1995.

[17] N. P. Chotiros, A. M. Mautner, A. Løvik, Å. Kristensen, and O. Bergem, "Acoustic penetration of a silty sand sediment in the 110-kHz band," IEEE Journal of Oceanic Engineering, vol. 22, no. 4, pp. 604-614, 1997.

[18] K. L. Williams, D. R. Jackson, E. I. Thorsos, D. Tang, and S. G. Schock, "Comparison of sound speed and attenuation measured in a sandy sediment to predictions based on the Biot theory of porous media," IEEE Journal of Oceanic Engineering, vol. 27, no. 3, pp. 413-428, 2002. 


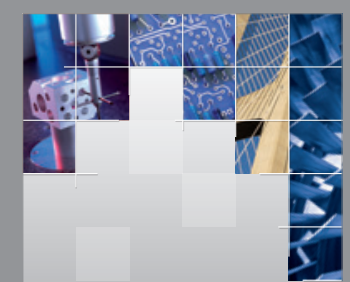

\section{Enfincering}
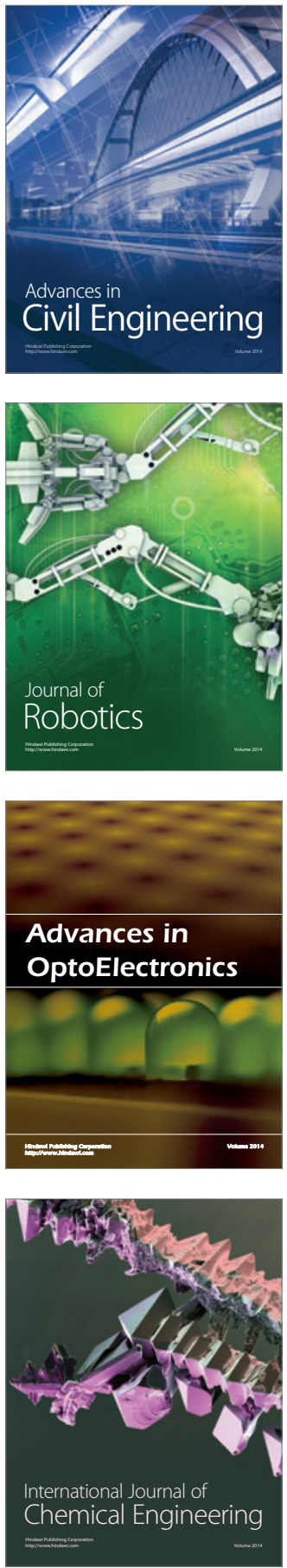

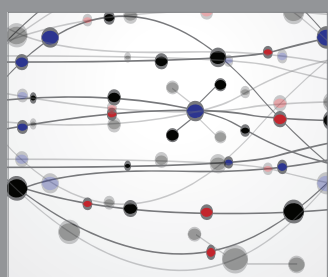

The Scientific World Journal

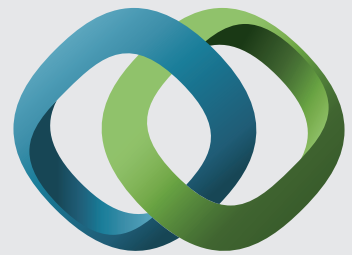

\section{Hindawi}

Submit your manuscripts at

http://www.hindawi.com
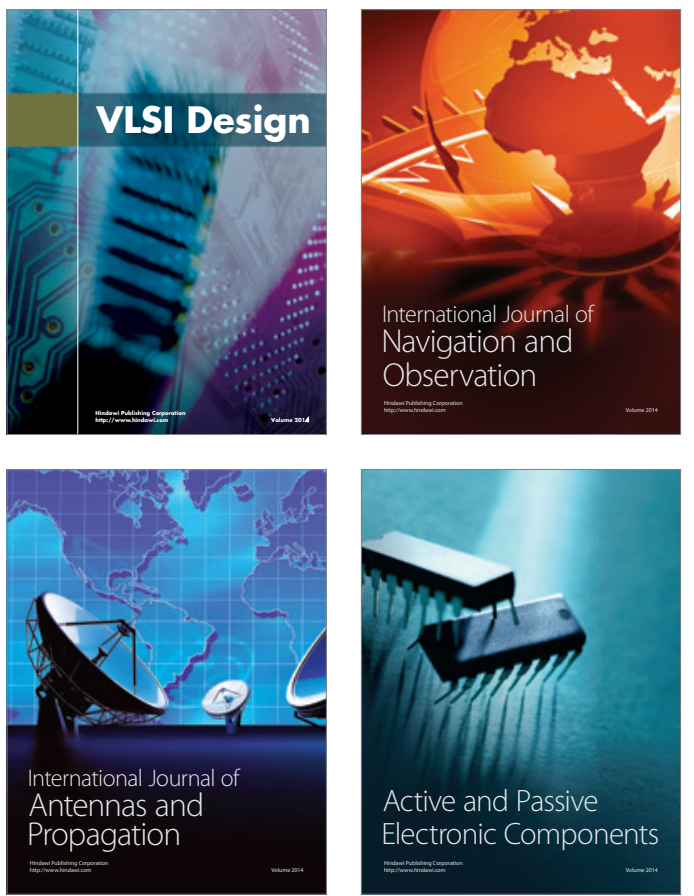
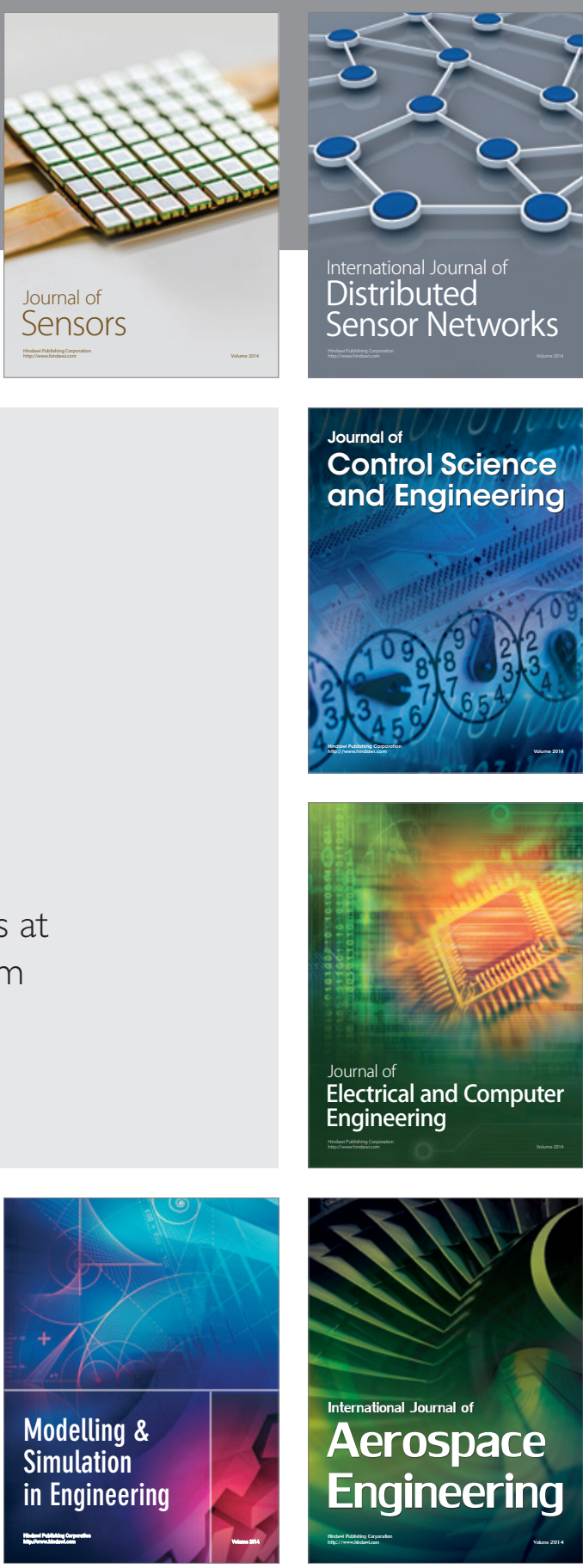

International Journal of

Distributed

Sensor Networks

Journal of

Control Science

and Engineering
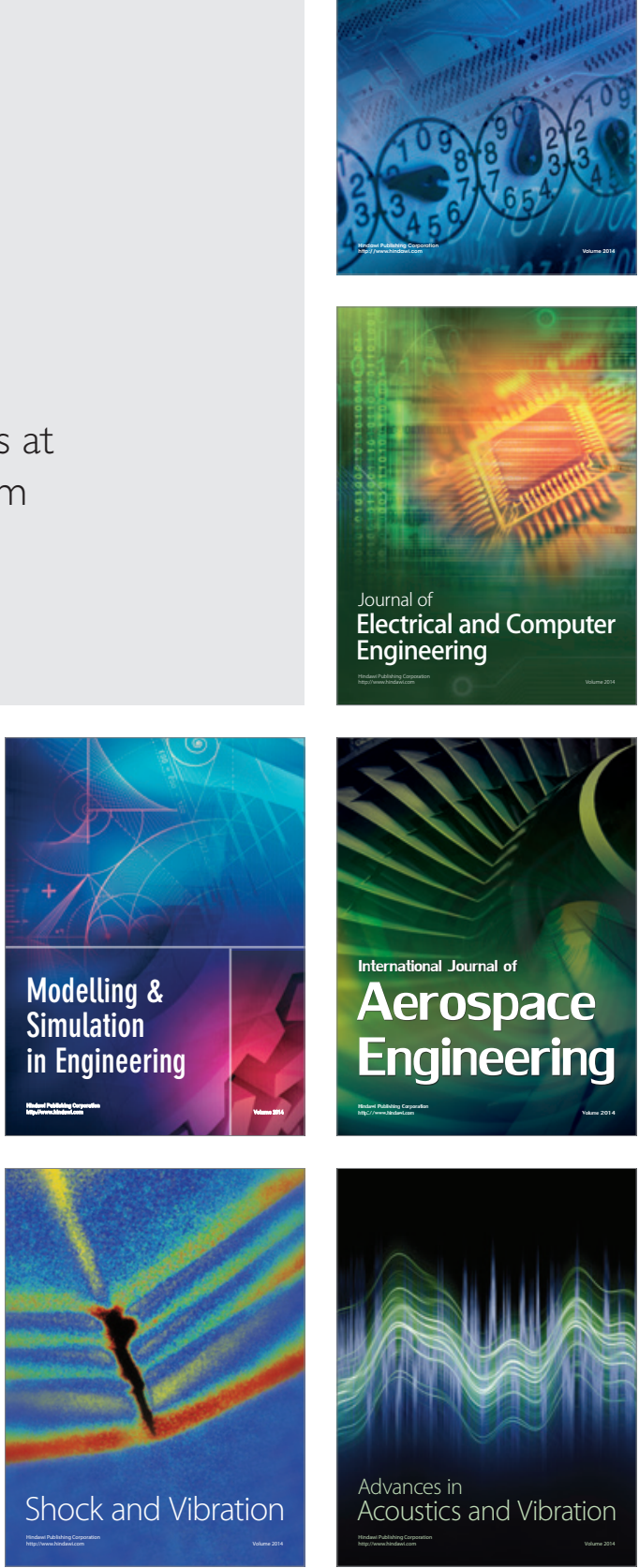